\title{
Cross-over type of supernumerary digastric muscle
}

\author{
Ž. Šink, N. Umek, E. Cvetko \\ Institute of Anatomy, Faculty of Medicine, University of Ljubljana, Slovenia
}

[Received: 7 October 2018; Accepted: 25 November 2018]

\begin{abstract}
A cross-over type asymmetric anomaly of the anterior belly of the right digastric muscle was observed during a cadaveric dissection of the submental region. Three irregularly-shaped supernumerary muscle bundles were found between the anterior bellies of the digastric muscles. Although the anomalies of the digastric muscles are often observed, this complicated pattern has not been previously reported. Our findings and previous reports illustrate the morphogenetic complexity of the anterior belly of the digastric muscle, and their potential importance in confounding clinical evaluation or complicating surgical procedures in the submental region. (Folia Morphol 2019; 78, 3: 647-650)
\end{abstract}

Key words: anatomic variant, anterior belly, asymmetry, submental region, human gross anatomy

\section{INTRODUCTION}

The digastric muscle has two bellies with separate embryologic origins and innervations: the posterior belly takes its origin from the medial site of the mastoid process and runs down and forward to the hyoid bone; while the anterior belly originates from the inferior border of the mandible close to the midline, and runs backwards superficial to the mylohyoid muscle. These two bellies are united by the intermediate tendon which attaches to the body and the greater horn of the hyoid bone. Embryologically, the anterior belly of the digastric muscle (ABDM) originates from the first pharyngeal arch and is innervated by the mylohyoid nerve; while the posterior belly of the digastric muscle (PBDM) originates from the second pharyngeal arch with innervation from the facial nerve [3].

The digastric muscle regulates the position of the hyoid bone and assists jaw movement, swallowing and chewing. Furthermore, it is an important surgical landmark, and accordingly variations in its normative anatomy may have important clinical implications.
It is therefore imperative to broaden the knowledge of the spectrum of possible anatomic dispositions of the digastric muscle. In the index report, we describe a complicated pattern of digastric muscle anomaly that has not been previously reported: a cross-over type supernumerary ABDM, discovered during a regional dissection of a 74-year-old male cadaver.

\section{CASE REPORT}

During the dissection of the submental region in a 74-year-old male cadaver, an asymmetric variation of the supernumerary ABDM was observed. Origins, insertions, shape, innervation and blood supply were subsequently investigated. Our anatomical evaluation revealed bilateral irregularly-shaped supernumerary ABDM lying superficial to the mylohyoid muscle, and measuring approximately $50 \mathrm{~mm}$ in length, $40 \mathrm{~mm}$ in width and $1 \mathrm{~mm}$ in thickness. One muscle bundle arose from an intermediate tendon of the right digastric muscle and the fascia covering the left mylohyoid muscle, close to the mylohyoid raphe (Fig. 1, *a); and the other from the 


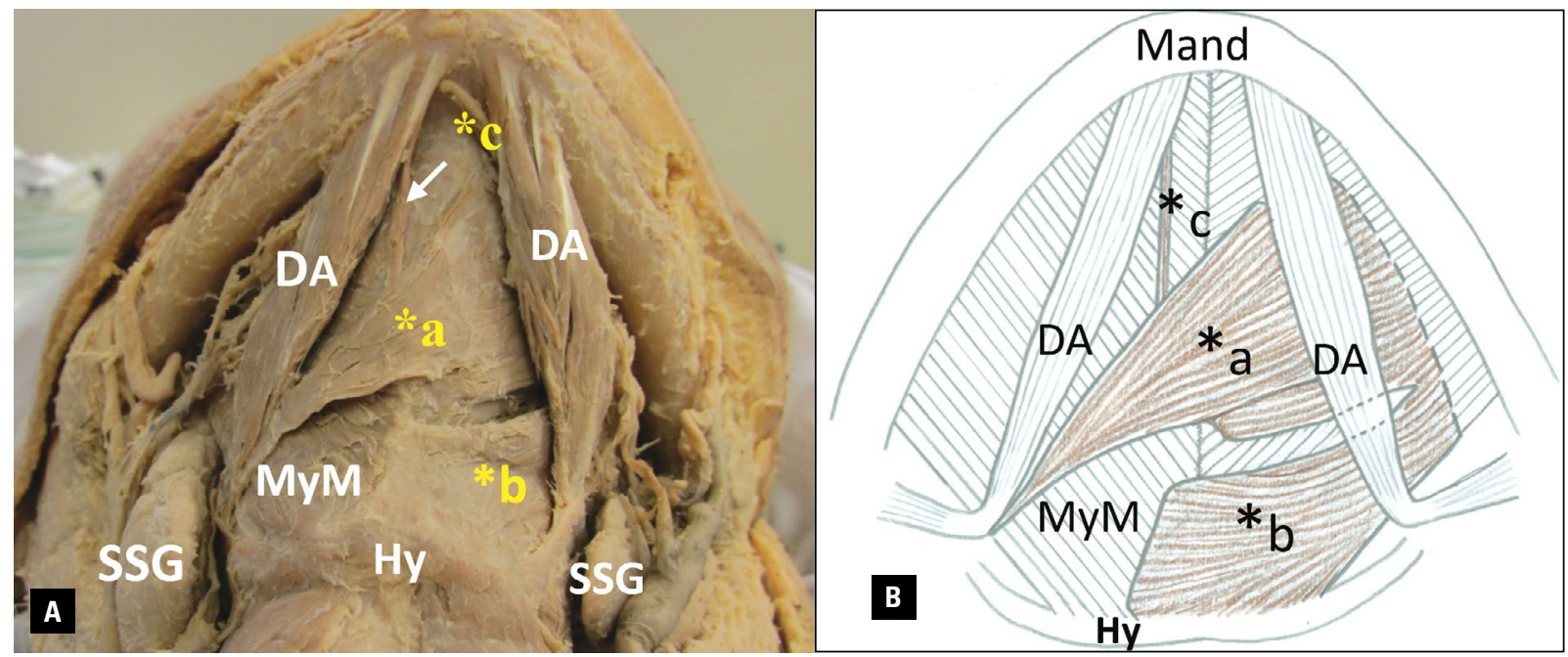

Figure 1. Dissection (A) and the interpretative diagram (B) showing the muscular pattern of the submental triangle, anterior view. ${ }^{*} a,{ }^{*} b,{ }^{*} \mathrm{C}$ - muscle bundles of the supernumerary anterior belly of the digastric muscle; DA — anterior belly of the digastric muscle, Mand — mandible; Hy — hyoid bone; MyM — mylohyoid muscle; SSG — submandibular salivary gland.

hyoid bone and fascia covering the right mylohyoid muscle, close to the mylohyoid raphe (Fig. 1, *b). Both bundles obliquely crossed the midline deep to the left ABDM and united approximately $10 \mathrm{~mm}$ before the point of fusion with the left mylohyoid muscle (about $10 \mathrm{~mm}$ from its attachment to the mylohyoid line). On the right, a thin muscle slip detached from the anterior margin of the supernumerary ABDM and attached to the medial border of the right $A B D M$ (Fig. 1, ${ }^{*} \mathrm{C}$ ). A thin fascia separated the supernumerary ABDM and the mylohyoid muscles. A lymph node was attached to the superficial surface of the supernumerary ABDM, beneath the left $A B D M$, surrounded with the twigs of the left mylohyoid nerve (Fig. 2D).

The supernumerary ABDM was innervated by the left mylohyoid nerve, passing between the left ABDM and the supernumerary ABDM. Nerve twigs penetrated the supernumerary ABDM to innervate the left mylohyoid muscle. On the right the mylohyoid nerve ran between the ABDM and the mylohyoid muscle, innervating both muscles. We were unsuccessful in determining the innervation of the narrow aberrant slip of the supernumerary ABDM on the right (Fig. 1, * $\mathrm{C}$ ). The left submental artery and the left submental vein provided vascular supply to the supernumerary ABDM.

Further dissection revealed that the PBDM, as well as the mylohyoid, geniohyoid and infrahyoid muscles, exhibited normal anatomy on both sides. No other muscular anomalies were found in the suprahyoid and infrahyoid regions.

\section{DISCUSSION AND CONCLUSIONS}

Several variations in shape, length and innervation of digastric muscle have been reported in literature. The anterior belly frequently exhibits accessory musculature, mainly as accessory bellies, muscular bundles and slips. ABDM variants have been described more frequently as unilateral $[2,7]$ than bilateral $[4$, 9]. Nevertheless, a case-based analysis by Mangalgiri et al. [6] concluded that unilateral and bilateral variations occur equally.

Many authors have proposed a classification of $A B D M$ variants. De-Ary-Pires et al. [3] identified five types of $A B D M$ variants based on the numbers of the anterior bellies and extra muscle slips. According to this division, our muscular variant could be considered as "Anterior Belly Type II". Fujimura et al. [4] proposed a classification based on the insertion of $A B D M$ on the mandible or the mylohyoid muscle; the insertion of the index muscular variant is on the mylohyoid muscle. Furthermore, Ozgur et al. [7] classified the ABDM variations either as "the digastric fossa type" with homolateral origins and insertions of accessory bellies; or "the crossover type" with midline crossing of accessory ABDM, with or without joining the mylohyoid muscle [7]. Based on this classification, our case could be classified as the crossover type.

From an embryological perspective, the most likely explanation for our observed anatomical variant is the heterogeneity in embryological development of the first pharyngeal arch. Mesodermal differentiation 

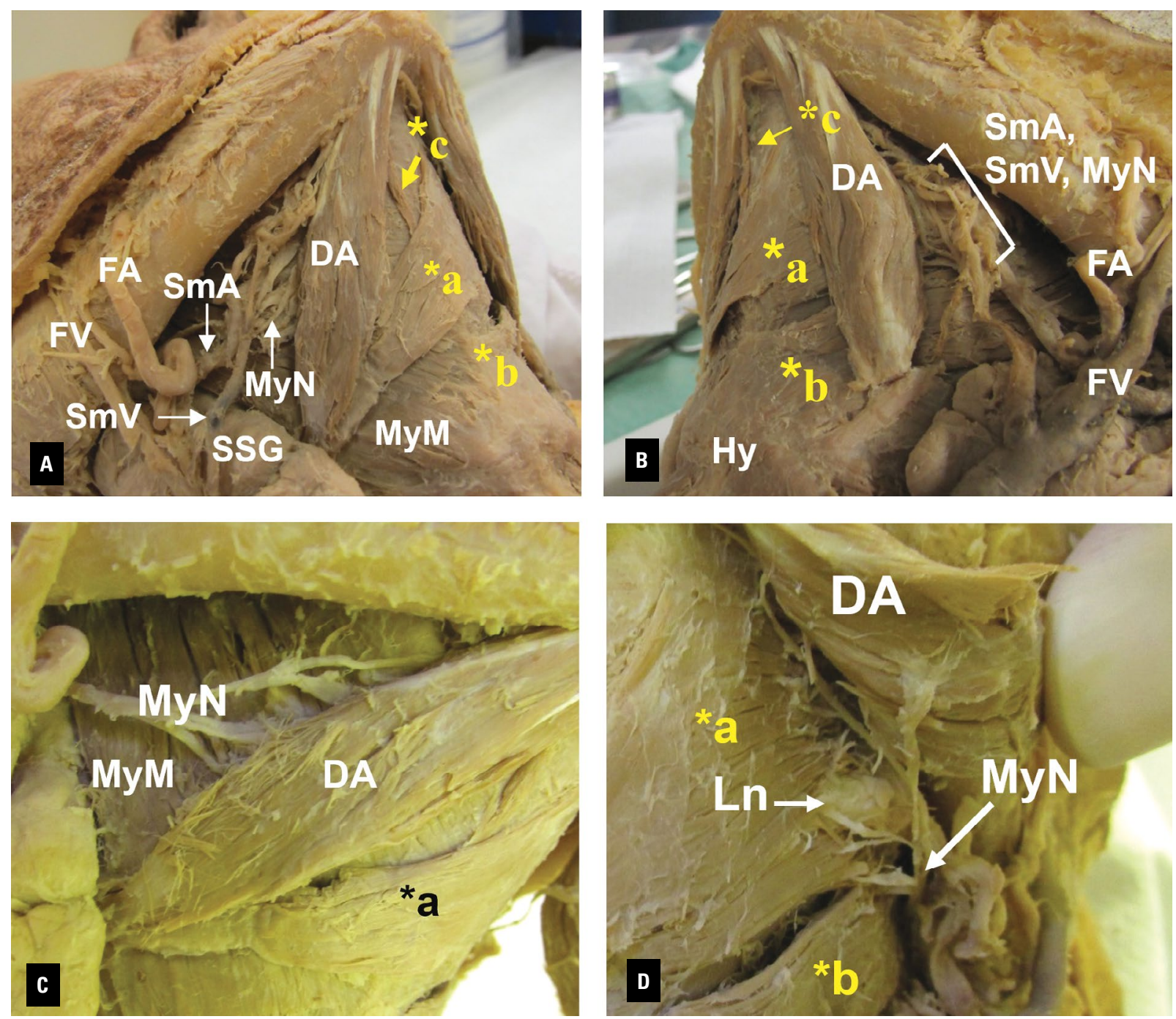

Figure 2. Supernumerary anterior belly of the digastric muscle $\left({ }^{*} \mathrm{a},{ }^{*} \mathrm{~b},{ }^{*} \mathrm{c}\right)$ from right $(\mathbf{A})$ and left (B) showing the neurovascular supply of the muscles in the submental triangle. Innervation of the muscles in the submental triangle after blood vessel removal, from right (C) and left (D), left DA is reflected; FA — facial artery; FV — facial vein; SmA — submental artery; SmV — submental vein; MyN — mylohyoid nerve; Hy — hyoid bone; MyM — mylohyoid muscle; DA — anterior belly of digastric muscle; Ln — lymph node.

deficiencies of the arch and abnormal neural crest cells migration patterns could be the underlying cause of ABDM duplication and multiplication [5]. Accessory muscle fibres may have crossed the midline due to the proximity of pharyngeal arches [1]. In our case, no anomalies in the vascularisation and innervation of the digastric muscles were observed. According to the innervation classification proposed by Sakamoto and Akita [8], our asymmetric variation of the supernumerary ABDM presents a digastric dominance.

In terms of clinical correlation, the described anatomical variant of accessory digastric bellies modifies the topographic anatomy of the submental and submandibular triangles (Level I, Robbins' classification) and may therefore bear considerable significance in plastic and reconstructive surgery, especially in creation of myocutaneus flaps; in diagnostic approaches to submental lymphadenopathies such as lymphnode biopsy; and in emergency interventions in the suprahyoid area of the neck. Guelfguat et al. [5] emphasized that asymmetrical ABDM variations could be easily mistaken for pseudomasses or pathological lymph nodes. Furthermore, they could also be mistaken for benign or malignant cervical masses and could potentially cause facial asymmetry. It is therefore important to stress that consideration of $A B D M$ variations could help prevent errors in clinical evaluation, diagnostic imaging interpretation and surgical procedures. 


\section{Acknowledgements}

We thank the Slovenian Research Agency for financial support within the framework of the Programme Group P3-0043. We are also grateful to Ivan Blažinovič for the dissection work, to Mark Slak for the figure labelling, and to Dr. Chiedozie K. Ugwoke for the manuscript proofreading.

\section{REFERENCES}

1. Andreo JC. Caldas Navarro JA, Toledo Filho JL. Anatomical study on the variations of the anterior belly of the digastric muscle. Rev Chil Anatomía. Sociedad Chilena de Anatomía. 1997; 15(2): 111-114.

2. Celik HH, Aldur MM, Ozdemir B, et al. Abnormal digastric muscle with unilateral quadrification of the anterior belly. Clin Anat. 2002; 15(1): 32-34, doi: 10.1002/ca.1088, indexed in Pubmed: 11835541.

3. De-Ary-Pires B, Ary-Pires R, Pires-Neto MA. The human digastric muscle: patterns and variations with clinical and surgical correlations. Ann Anat. 2003; 185(5): 471-479, doi: 10.1016/S0940-9602(03)80110-3, indexed in Pubmed: 14575275 .
4. Fujimura $\mathrm{A}$, Onodera $\mathrm{M}$, Feng $\mathrm{XY}$, et al. Abnormal anterior belly of the digastric muscle: a proposal for the classification of abnormalities. Anat Sci Int. 2003; 78(3): 185-188, indexed in Pubmed: 14527134.

5. Guelfguat M, Nurbhai N, Solounias N. Medianaccessorydigastric muscle: radiological and surgical correlation. Clin Anat. 2001; 14(1): 42-46, doi: 10.1002/1098-2353(200101)14:1<42::AIDCA1007>3.0.CO;2-O, indexed in Pubmed: 11135397.

6. Mangalagiri AS, Razvi MR. Variations in the anterior belly of diagastric. Int J Health Sci (Qassim). 2009; 3(2): 257-262, indexed in Pubmed: 21475546.

7. Ozgur Z, Govsa F, Ozgur T. The cause of the difference in the submental region: aberrant muscle bundles of the anterior belly of the digastric muscle. J Craniofac Surg. 2007; 18(4): 875-881, doi: 10.1097/scs.0b013e31806844da, indexed in Pubmed: 17667681.

8. Sakamoto Y, Akita K. Supernumerary muscle bundles in the submental triangle: their positional relationships according to innervation. Surg Radiol Anat. 2004; 26(3): 245-253, doi: 10.1007/s00276-004-0227-1, indexed in Pubmed: 14872289.

9. Yamazaki Y, Shibata M, Ushiki T, et al. Bilateral, asymmetric anomalies of the anterior bellies of digastric muscles. J Oral Sci. 2011; 53(4): 523-527, indexed in Pubmed: 22167040. 